Article

\title{
Non-Linear Microscopy: A Well-Established Technique for Biological Applications towards Serving as a Diagnostic Tool for in situ Cultural Heritage Studies
}

\author{
Meropi Mari * and George Filippidis $(\mathbb{D}$ \\ Institute of Electronic Structure \& Laser, Foundation for Research and Technology-Hellas, 71110 Heraklion, \\ Greece; filip@iesl.forth.gr \\ * Correspondence: mmari@iesl.forth.gr
}

Received: 16 December 2019; Accepted: 10 February 2020; Published: 14 February 2020

check for updates

\begin{abstract}
A range of sophisticated imaging techniques have been developed in recent years that can reveal the surface structure of cultural heritage objects with varying precision. In combination with various spectroscopic methods, they allow the study of the chemical composition of the object; thus, conclusions can be drawn about the origin of the object or its initial components, method, or time of creation, authenticity, mechanisms of degradation, and ways of further conservation. At present, different techniques can be applied to a wide range of cultural heritage objects, such as varnishes, paintings, archaeological objects, binding media, paper-based documents, parchments, marbles, frescoes, as well as various objects made of leather, fabric, stone, ceramics and glass, wood, or metal. One of the main needs in the study of cultural heritage $(\mathrm{CH})$ is the transportability/portability of the research equipment, since many pieces under investigation cannot be moved to the laboratory, either because of their size, inseparability (for example, frescoes on walls, mural paintings in caves), or the threat of damage. In this work, we briefly overview the main optical- and laser-based methods used for the study of cultural heritage objects indicating the scope of their application, and we focus on the applications of non-linear microscopic methods for the investigation of a series of artifacts. We also discuss all the requirements for the construction of a prototype transportable non-linear optical system that will be used as a novel diagnostic tool for in situ studies of $\mathrm{CH}$ assets. The availability of such a transportable workstation will significantly improve the study and characterization of various types of $\mathrm{CH}$ objects and will constitute an extremely useful diagnostic tool for heritage scientists dealing with a variety of investigations.
\end{abstract}

Keywords: cultural heritage; laser-based diagnostic techniques; degradation and aging; non-linear microscopy; multi-photon excitation fluorescence; transportable system

\section{Introduction}

Artworks such as paintings consist of a variety of layers with different chemical composition [1]. A painted artwork is a complex multi-layer structure, as shown in Figure 1. A typical layer is the "support" layer, which is the base of the painting and protects it from a range of mechanical impacts. There is a wide range of support layers, which may include paper, fabric or canvas, plaster, glass, wood, metal, or rock (frescoes, petroglyphs). In addition, the support layers are usually covered by various glues to ensure sufficient adhesion. A canvas or fabric support layer is usually attached on stable, knot-free, usually wooden, material called a "stretcher". There is also the "ground" layer that is between the paint and support layer usually made of gesso, which usually contains chalk or even white lead pigment. The "paint" layer is a mixture of the pigment (fine powder) and a binder 
(a substance that keeps the powder uniform). Pigments are ground colored materials either of inorganic (e.g., ultramarine blue) or organic (e.g., lakes such as madder, cochineal) origin [2]. Some of them can be found in nature as mixtures in minerals, and others are prepared in the lab. There is a wide range of binders. Widely-used binders are linseed oil, egg tempera, animal glue, and gum arabic. A painted artwork may consist of a variety of paint layers, underdrawings, and underpaintings. Finally, the "varnish" layer is a transparent coating that provides additional protection to the painting or acts as a glazing agent determining the visual perception of the layers underneath. It is often made of natural (dammar, mastic, colophony) or synthetic (Regalrez, Vinavil, Paraloid) resin [2,3].

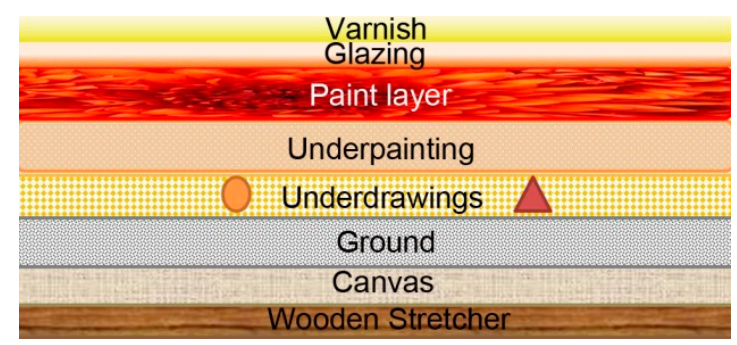

Figure 1. Typical structure and layers of an oil paint artwork.

\subsection{Problem Statement: Factors that Cause Degradation of a Cultural Heritage (CH) Object}

Cultural heritage objects suffer from various defects and degrade with time. Aging, inappropriate handling, pollution, temperature, light, bacteria or insects, and other factors may affect the color of the object, or may cause cracks, chemical reactions, or layer detachment and lead to damage. Degradation phenomena related to paintings, paper, plaster, glass, wood, and metal have been thoroughly studied [4-10]. The earlier the restoration begins, the more effective and the less expensive it is. That is the reason why conservators need to have an early diagnosis of any ongoing damage to the painting. For this reason, they require a number of diagnostic methods to be able to recognize any deterioration. Clearly, these methods should be non-destructive; otherwise the diagnostics can be more harmful than the deterioration itself. There has been research on works of art, by computational modeling, and physical and chemical studies, that improve our prediction of artwork appearance before degradation and establish effective preventive conservation strategies [4].

Other factors that can damage culture and history are forgery and art fraud. Art forgery is the act of creating a copy of an existing piece of art or mimicking the style of another artist, employing similar materials to deceitfully assign or date artworks. In this case, such artworks can be identified as original and auctioned for a high price. In such cases, independent scientific techniques are extremely necessary to recognize forgery. This requires deep knowledge of art history and the artists' work, as well as the materials available at the time the artwork was created [11].

The removal of aged or damaged layers from the surface of paintings is a delicate and crucial intervention in cultural heritage $(\mathrm{CH})$ conservation. This irreversible action gets particularly complicated considering the variety of materials that may be present within a painted work of art, as well as the exceptional sensitivity of the original surfaces to environmental conditions such as heat, light, and pollution. Lasers hold an important role among the available cleaning methodologies, as they enable high control and accuracy and material selectivity. Still, prior to their implementation, it is imperative to optimize the cleaning parameters by employing novel diagnostic techniques, so to ensure that any potential implications to the remaining materials are minimal and well understood [12]. 


\subsection{Diagnostic Imaging Methods in the Service of Cultural Heritage}

A number of analytical and diagnostic techniques have been employed, ranging from micro-destructive ones in which sampling is necessary, to non-contact and non-invasive ones. A brief overview of the main optical and laser-based methods that are well established and used for the study of cultural heritage objects are presented in the next section.

\subsubsection{Laser-Induced Breakdown Spectroscopy (LIBS)}

Laser-Induced Breakdown Spectroscopy (LIBS) is a spectrochemical technique enabling multi-element analysis of the materials that constitute an artwork. It is increasingly employed in archaeological and historical studies $[13,14]$. LIBS is classified as a micro-invasive technique. Its micro-destructiveness, with ablated sample portions in the order of fractions of micrograms and induced damage are virtually invisible to the naked eye. It has the potential for fast multi-elemental analysis and capability of simultaneous detection of major and trace elements [15]. Moreover, LIBS requires no surface preparation and is capable of in situ depth profile analysis, if spectra on the same spot are recorded individually [16]. Its equipment can be easily converted into portable instruments for in situ analyses of pieces of art [17-19]. Finally, the mobile LIBS instruments and experimental modules open up a wide field of opportunities for analytical campaigns carried out on location; at the museum, the conservation laboratory, or even outdoors, such as, for example, at an excavation or historical site [18].

\subsubsection{Holography}

Holography and holographic-related interferometry are modern tools to art conservators or researchers. These methods are exploited to reveal structural faults and mechanical discontinuities in the bulk of a piece of art. Holographic analysis is based on the study of interference patterns as an effect of controlled surface reflection of diffused laser beams. The surface is kept unaffected during holographic imaging; thus, it is a non-destructive technique [20]. Three-dimensional imaging provided by holography has motivated the development of digital holographic imaging methods based on computer generation of holograms as a holographic display or a holographic printer [21]. The holographic printing technique relies on combining digital 3D object representation and encoding of the holographic data with recording of analog white light viewable reflection holograms.

\subsubsection{Multi-spectral Imaging}

Multi-spectral and hyperspectral modalities collect images of an object in a series of spectral windows. They are efficient methods for collecting millions of spectra since a spectrum is measured for each spatial pixel. It relies on the recording of sequential images at various spectral bands ranging from ultraviolet (UV)-visible to near-infrared (NIR) [22,23]. Multi-spectral imaging enables efficient capturing of spectral reflectance at millions of pixels simultaneously [24]. Thus far, multi-spectral imaging is the unique technique that has been applied directly to a map [25]. The advantage of such a non-invasive technique is to examine any region on the map and not be restricted to a few spots. The reflectance spectra can contribute to the identification of artists' materials including pigments and paint binders [26]. The optimization of the implementation of hyperspectral imaging reflectance cameras in the analysis of artworks, paintings, and art on paper is also another research field with high importance [26].

\subsubsection{Raman Spectroscopy}

Raman spectroscopy has grown to be one of the most employed techniques for the investigation of art objects. The approach has several advantageous properties, and the minimally destructive character of the technique allowed it to be used for in situ investigations for obtaining valuable chemical information $[19,27,28]$. One of the most common applications is the authentication of a $\mathrm{CH}$ 
object [29]. Another important contribution of Raman spectroscopy to cultural heritage varies from the investigation of the causes of alteration and degradation $[29,30]$ to the subsequent conservation and restoration recommendations [31]. However, compared with laboratory approaches, it would be useful to take advantage of the small spectral footprint of the technique and use Raman spectroscopy to study the spatial distribution of different compounds. An in situ Raman mapping system has been developed to relate chemical information with its spatial distribution. Challenges for the development include the need for stable positioning and proper data treatment [32]. The non-destructive character of Raman spectroscopy strictly depends on the experimental conditions of the analysis.

\subsubsection{Fourier-Transformed Infrared Spectroscopy (FTIR)}

The FTIR spectroscopy represents a valuable tool for the analysis of different types of historical artifacts due to its sensitivity and specificity [33]. The technique can be successfully applied for characterization of metallic artifacts [34], paper artifacts [35], or historical textiles [36]. Chemical changes because of materials aging can be observed and sometimes quantified using FTIR spectroscopy, which is important especially for art conservation efforts [37].

An FTIR microscope consists of an FTIR spectrometer combined with an optical microscope. Infrared spectroscopy is able to determine both inorganic and organic phases and provide information on the restoration process [38]. The total reflection mode is widely used in portable FTIR equipment [39], since it can acquire in situ spectra without the need to be in contact with the surface under examination and has been implemented in various $\mathrm{CH}$ studies. Specifically, Attenuated Total Reflection (ATR) and External Reflection (ER) are proven effective FTIR techniques for polymer identification and are beginning to appear in conservation labs [40]. Furthermore, an ATR-FTIR spectroscopic technique has been developed for the analysis of Chinese handmade papers [41]. The technique has been applied to Chinese handmade papers, followed by papers from ancient books and arts collected in libraries and museums. This study has indicated that FTIR is an efficient analytical method to identify fiber types of library/museum papers of unknown origin. Moreover, information about the degree of crystallinity and state of deterioration of cellulosic fibers can be extracted from FTIR spectra.

\subsubsection{Optical Coherence Tomography (OCT)}

OCT is a fast, high-resolution 3D scanning method based on a Michelson interferometer. Mapping produces either cross-section images or en-face images at various depths; a series of these can be combined to give 3D information. It is particularly suited to the examination of transparent layers, such as varnishes and glazes, although under certain circumstances it is capable of imaging the layer structure as far as the preparation layer [42]. The OCT examination that is non-invasive and non-contact, includes the subsurface layer of historic paintings at the microscale; paint and varnish layers [42,43], as well as other historic objects [44,45]. The reported applications for cultural heritage objects involve examination of wall paintings [46], paintings on glass support [47], stained glass [48], and semi-precious stones such as jade [44,49] and amber. OCT has the potential to monitor the conservation process-the removal of secondary layers, as well as the consolidation treatment [50], may be observed and evaluated fast. It may be possible to obtain layer structure to a greater depth and higher resolution by varying the parameters of the instrument, such as wavelength and bandwidth of the light source. An optimum spectral window for OCT was found to be $\sim 2.2 \mu \mathrm{m}$, through the study of the transparency of pigments as a function of wavelength on various historic pigments in linseed oil and egg tempera [51].

\subsubsection{Terahertz Time-Domain imaging (THz-TDI)}

Terahertz radiation is capable of deep penetration through numerous and different media; thus, it has been used to identify ancient manuscripts or hidden text in a variety of studies $[52,53]$. THz radiation lies in the far-infrared region of the electromagnetic spectrum ranging from 0.1 to $10 \mathrm{THz}$ $\left(3.3-333 \mathrm{~cm}^{-1}\right)$. One of the biggest advantages of $\mathrm{THz}$ is that, as submillimeter waves, they can 
penetrate through a wide variety of materials, such as paper, wood, masonry, clothing, plastic, and ceramics, which are usually opaque to both visible and infrared radiation. THz radiation can be used for hidden layer imaging since it trespasses further into the sample than infrared techniques, commonly used in art examination [54]. THz-TDI has been used to study various museum objects around the world. Commercial THz pulsed TDI systems have revealed multi-layer fabric sheets, mummies [55], and underpainting layers [56], but they mainly have investigated the structural information of wall paintings and their preparation layer that is related to the painting technique, which varies according to the origin of the artwork and is crucial for conservation planning [57]. Successive works have demonstrated the high potential of THz pulsed TDI for use as an analytical tool for panel paintings [58,59], Japanese panel paintings and screens [60], and oil paintings on canvas [61].

\subsubsection{Laser-Induced Fluorescence Spectroscopy (LIF)}

LIF spectroscopy is a non-destructive surface analytical method to identify the chemical composition of organic or inorganic compounds. The fluorescence of every material is unique and specific to its molecular structure. Different materials display differences in the fluorescence curves; their shape and wavelength for maximum fluorescence [62]. It permits a large scanning area; it can identify the binding media on frescoes, but also gives information on the pigment distribution and degradation [63]. Due to limitations concerning the low spectral resolution and the modest distinction in spectral signatures, LIF is being combined with other spectroscopy techniques, such as Raman and LIBS, to investigate model wall paintings and heritage stone samples [64].

\subsubsection{Photoacoustic Microscopy (PA)}

Photoacoustic microscopy (PA), a rapidly growing imaging method widely employed in biomedical research, exploits the ultrasonic acoustic waves, generated by light from a pulsed or intensity-modulated source interacting with a medium, to map the spatial distribution of absorbing components. Having over three orders of magnitude higher transmission through strongly scattering media, compared to light in the visible and near-infrared, the photoacoustic signal offers substantially improved detection sensitivity and achieves excellent optical absorption contrast at increased penetration depths. Photoacoustic images have been collected from miniature oil paintings on canvas [65,66]. In addition, it can precisely control the material removal on stone objects and determine the substrate's damage threshold [67]. A simple case application related to the ablation of black graffiti from medium-coarse grained white marble was selected to demonstrate the high potential of this approach [67]. By adjusting the detection bandwidth of the optically induced ultrasonic waves, photoacoustic imaging can be employed to investigate a broad variety of artifacts having diverse optical properties and geometrical profiles, such as manuscripts, glass objects, plastic modern art, or even stone sculpture. PA data statistical analysis and correlation with conventional imaging techniques such as stereomicroscopy, Scanning Electron Microscopy (SEM), and confocal microscopy, has shown accuracy on the prediction of cleaning level, as well as the onsets for effective cleaning and substrate damage [67].

\subsubsection{Pump-Probe Spectroscopy}

Near-infrared femtosecond pump-probe optical microscopy has expanded the range of detectable molecular signatures [68] to include signals from excited state absorption, ground state depletion, and stimulated emission [69]. This microscopy technique was mainly developed for biomedical imaging. Extension of pump-probe microscopy from biological pigments to samples of artists' pigments has already yielded promising preliminary results [70]. Pump-probe microscopy offers an exciting alternative to the current techniques used for identifying organic dyes. Work is currently underway to create a pump-probe spectral database for a variety of organic and inorganic pigments [71]. Pump-probe has recently presented its high-resolution mapping ability, through the study on mixtures of pigments, and has proved its potential to resolve individual coloring components in natural pigments [72]. 


\subsection{Non-linear Microscopy}

Non-linear imaging microscopy shows many advantages compared to other microscopy methods. It is capable of intrinsic three dimensional (3D) subsurface sectioning increased penetration depths while still avoiding damage to objects through photobleaching or phototoxicity phenomena in the out-of-focus area $[73,74]$. Second and third harmonic generation ensure minimal sample disturbance, as they are scattering phenomena with little energy being deposited in the sample [73]. However, the same beam that enables second and third harmonic generation may also be absorbed through other non-linear processes, such as Multi-Photon Excitation Fluorescence (MPEF). A significant advantage of non-linear microscopy (NLM) is that all the aforementioned signals are generated simultaneously in the focal volume of the examined object from a single laser source. Thus, they provide unique complementary information related to the chemical composition of the sample, the centrosymmetry of its molecules, and the structural delineation of the material.

The main advantages and limitations of some of the aforementioned techniques are presented in Table 1. Non-linear microscopy (NLM) diagnostic modalities are also included in Table 1.

Table 1. Advantages/limitations of some of the most commonly employed optical- and laser-based diagnostic techniques on cultural heritage $(\mathrm{CH})$ objects. Characteristic applications of each modality are also shown. NLM, non-linear microscopy; OCT, optical coherence tomography.

\begin{tabular}{|c|c|c|c|}
\hline Modality & Advantages & Limitations & $\mathrm{CH}$ objects - Applications \\
\hline NLM & $\begin{array}{ll}\text { - } & \text { Non or minimally invasive } \\
\text { - } & \text { Fast scanning } \\
\text { - } & \text { Single laser source } \\
& \text { information }[75,76]\end{array}$ & $\begin{array}{l}\text { - Limited depth in highly } \\
\text { scattering/absorbing media } \\
{[76-78]}\end{array}$ & $\begin{array}{l}\text { Varnishes [79], lining glues [80,81], } \\
\text { historical coatings [82], } \\
\text { parchments [83], paint [75], } \\
\text { corrosion layer [84] }\end{array}$ \\
\hline OCT & $\begin{array}{ll}\text { - } & \text { Non-invasive, wide-field } \\
\text { - } & \text { Fast scanning } \\
\text { - } & \text { Thick sample identification } \\
\text { - } & \text { Portable [44] }\end{array}$ & $\begin{array}{ll}- & \text { Lacks specificity [77] } \\
\text { - } & \text { Low spatial resolution [44] }\end{array}$ & $\begin{array}{l}\text { Varnish and glaze layers of } \\
\text { paintings [43], semi-transparent } \\
\text { solids [44,85,86], glazed ceramics } \\
\text { [87], parchment }[88] \\
\text { underdrawings }[42,44]\end{array}$ \\
\hline Raman & $\begin{array}{l}\text { - Chemical } \\
\text { sensitivity/fingerprint of } \\
\text { the material } \\
\text { - } \quad \text { Portable for in situ } \\
\text { investigation [89] } \\
\text { - } \quad \text { User-friendly [90] }\end{array}$ & $\begin{array}{ll}\text { - } & \text { Slow image acquisition [91] } \\
\text { - } & \text { Limited in 2D for highly } \\
\text { scattering media } \\
\text { - } & \text { Fluorescence background } \\
& {[92]}\end{array}$ & $\begin{array}{l}\text { Rocks and minerals [93], } \\
\text { gemstones [94], corrosion layers } \\
\text { [95], glues [96], varnishes [97], } \\
\text { pigments on stone sculptures [18] } \\
\text { or on painted plaster [19], paper } \\
\text { [98], parchments and inks [99] }\end{array}$ \\
\hline Photoacoustic & $\begin{array}{ll}\text { - } & \text { Increased } \\
\text { penetration depths } \\
\text { - } & \text { Delineation of } \\
& \text { underdrawings }[66,100]\end{array}$ & $\begin{array}{l}\text { - Low spatial resolution } \\
\text { Use of immersion medium } \\
\text { on the investigated surface } \\
\text { (surface sunk into distilled } \\
\text { water or ultrasound gel) } \\
\text { [100] }\end{array}$ & $\begin{array}{l}\text { Acrylic paints on canvas [65], } \\
\text { sketch lines and underdrawings } \\
\text { [66], multi-layered documents and } \\
\text { paper sheets [100], graffiti } \\
\text { cleaning on white marble [67] }\end{array}$ \\
\hline $\begin{array}{l}\text { Multi-spectral } \\
\text { imaging }\end{array}$ & $\begin{array}{ll}\text { - } & \text { Simple/inexpensive set-up } \\
\text { - } & \text { Portable [101] } \\
\text { - } & \text { Reveals underdrawings } \\
& {[24]}\end{array}$ & $\begin{array}{ll}\text { - } & \text { Limited spectral resolution } \\
\text { Limited color } \\
\text { representation [102] }\end{array}$ & $\begin{array}{l}\text { Distribution and identification of } \\
\text { several pigments across a map } \\
\text { [25], monitor the cleaning of } \\
\text { marbles }[103,104], \text { multi-variate } \\
\text { combinations of pictorial } \\
\text { materials [105] }\end{array}$ \\
\hline $\mathrm{THz}$ & $\begin{array}{l}\text { Thick multi-layered } \\
\text { samples determination } \\
\text { - } \quad \text { Reveals underdrawings } \\
\text { [57] } \\
\text { - } \quad \text { Portable [106] }\end{array}$ & $\begin{array}{l}\text { - Low spatial resolution } \\
\text { - Expensive }\end{array}$ & $\begin{array}{l}\text { Fabric and mummies [55,107], } \\
\text { western wall paintings [56], oil } \\
\text { paintings [61,108], Japanese panel } \\
\text { paintings and screens [60] }\end{array}$ \\
\hline
\end{tabular}




\subsection{Non-linear Imaging as a Tool to Serve Cultural Heritage Studies}

Non-linear microscopy techniques (NLM), such as MPEF, second harmonic generation (SHG), and third harmonic generation (THG), are well-established techniques for biological research [109-114]. These techniques under different modalities provide new insights for the assessment of appropriate conservation methods that have to be applied for various $\mathrm{CH}$ objects of high artistic or cultural significance $[79,115]$. Recent studies have demonstrated the potential of these techniques for depth resolved imaging of materials in cultural heritage, such as varnishes [79], lining glues [80,81], paintings [75], historical coatings [82], and corrosion layers on metal-based artifacts [84]. Fruitful key information concerning the determination of the different layers, precise thickness or surface topography, nature of the different materials, and cracks in the layers has been extracted.

Furthermore, ancient parchments, which are mainly composed of dermal fibrillar collagen, have been investigated [83]. Key information about collagen and gelatin signatures has been obtained in parchments and assessed by characterizing the denaturation of pure collagen reference samples. Along with denaturation, a strong decrease is observed in SHG signals, which are a structural probe of the fibrillar organization of the collagen at the micrometer scale [116].

\subsection{Synergy of Non-linear Techniques with other Imaging Modalities}

It is well known in a number of disciplines extending from biomedical science to art conservation and forensic science that there is not a single analytical technique that can give answers to all questions. This is particularly true in the study of historical paintings where the materials involved are numerous and heterogeneous. A multi-modality approach offers new complementary information by combining the strength while overcoming the limitations of individual techniques.

Specifically, NLM and OCT techniques have been combined for the study of model paintings [77]. It has been proved that non-linear imaging techniques can act synergistically with optical coherence tomography measurements providing complementary diagnostic capabilities for the precise in-depth characterization of various model painted artworks. The axial resolution of OCT and NLM are similar, while OCT in general is used with lower spatial resolution and a larger field of view. OCT is typically 3 to 4 orders of magnitude faster in image acquisition and offers extended penetration depths in comparison to NLM. Both OCT and the non-linear modality of THG are sensitive to refractive index discontinuities, while MPEF renders image contrast information between layers with different absorption properties. It has been demonstrated that OCT is capable of providing information from deeper layers of a model painted artwork while it cannot distinguish between two types of equally transparent varnishes. On the other hand, the MPEF modality presents limited penetration depths, while it is capable of discriminating different transparent varnishes based on the detected fluorescence intensity variation of the samples [77].

Furthermore, pump-probe optical microscopy has been combined with multi-photon fluorescence, and second harmonic generation contrasts image modalities to simultaneously investigate pigments in conjunction with their support layers in three dimensions with micrometer-scale spatial resolution. The combination of pump-probe with SHG could be a promising new way to study fibrous-based artworks and provide new insights into the methodology of creating watercolors, illuminated manuscripts, or ancient textiles. It can also shed light on the preparation techniques of the fibrous supports. The application of the pump-probe technique to thick paint layers featuring multiple pigments and heavy binder use was capable of extracting signal from the support at depths up to $90 \mu \mathrm{m}$ in paper and $300 \mu \mathrm{m}$ in cloth [117].

In another study, the combination of the non-linear optical modality of MPEF and photoacoustic imaging has proven effective for the high resolution stratigraphic analysis of multilayer art objects with emphasis on paintings. The high contrast complementarity provided by this bimodal approach has additionally been enhanced by post-processing analysis of the acquired MPEF signals using a novel algorithm, which is able to discriminate overlapping layers according to the non-linearity order and the optical parameters of the system. In addition, the combined images have been directly compared 
with cross-sectional bright field observations, validating the capabilities of the proposed diagnostic method in terms of measurement accuracy and imaging specificity [118].

Moreover, the modality of MPEF in combination with THG has been developed for the assessment of modifications following laser removal of varnish [119]. The structural and in-depth photochemical modifications induced upon ultraviolet laser removal of a dammar varnish coating on a photosensitive substrate have been assessed with NLM imaging. The results acquired through this work serve to understand the phenomena that are induced upon laser ablation and to determine the best operating conditions that ensure controlled removal of the varnish with minimal morphological and chemical modifications to the under-layers.

Additionally, non-linear imaging and terahertz time-domain spectroscopy have been employed as diagnostic tools for studies of works of art. It has been shown that non-linear imaging offers precise in-depth information from the outer layers, while terahertz imaging can reveal hidden objects and uncover information on highly absorbing organic compounds like small polycyclic aromatic hydrocarbons and their halogenated compounds [120].

It has to be noted that the identification of the safe limits for the use of the non-linear techniques for $\mathrm{CH}$ studies has been guided so far by the vast experience in biomedical applications. However, there is an increasing attention and need for the determination of the exact specifications for the safe irradiation of various $\mathrm{CH}$ objects. There are recent MPEF studies performed on a series of commercial acrylic paints that highlighted the dependence of the emitted fluorescence intensity on material composition and illumination conditions. This work evaluates the damage of near-infrared femtosecond pulsed lasers and establishes safe laser thresholds on a variety of painted artworks [121]. However, further studies employing different excitation wavelengths, pulse durations, and repetition rates are necessary to evaluate and determine the optimum parameters for the safe implementation of NLM on CH objects.

\section{Materials and Methods}

\subsection{Multi-Photon Excitation Fluorescence (MPEF)}

The MPEF imaging technique is an ideal, diagnostic tool for the precise (lateral resolution $\sim 500 \mathrm{~nm}$ and axial resolution $\sim 2 \mu \mathrm{m}$ ) thickness determination of multi-layered samples [75,78]. MPEF is a non-linear optical procedure where the non-linear process depends on the intensity of the incident laser irradiation [73]. MPEF measurements are able to give some indication of the chemical composition of artifacts. The common case of MPEF is Two-Photon Excitation Fluorescence (TPEF). During TPEF, one photon having energy approximately equal to half the energy difference between the excited and the ground state of a fluorescent molecule interacts with the electron in order to excite it to an intermediate virtual state where it will remain for an extremely short time in the order of 1 femtosecond (fs) $[73,74]$. If the spatial and temporal density of the incident beam is high enough, there is a finite probability that a second photon will interact with the electron of the virtual state resulting in the transition of the electron to the excited state. The consequent de-excitation of the electron returning to the ground state emits a single fluorescent photon of higher energy to the incident photons.

\subsection{Second and Third Harmonic Generation (SHG, THG)}

NLM techniques are based on physical processes in which a molecule can be excited by simultaneous interaction with two or more photons in the same quantum event [73]. SHG and THG are second and third order non-linear scattering coherent phenomena in which two or three photons of $\omega$ angular frequency are simultaneously converted in a photon of $2 \omega$ or $3 \omega$ angular frequency, respectively. SHG enables the detection of high degree-organized structures without inversion symmetry, such as stacked membranes and arranged proteins (e.g., collagen) [80,111]. THG allows the resolution of transparent interfaces, on the basis of local differences in refractive index and dispersion $[79,110,112]$. 


\subsection{Experimental Apparatus—Samples}

In the next section, two characteristic applications of non-linear microscopy to model painted artworks will be discussed. The experimental set-up used for the performance of the measurements has been described thoroughly in our previous works $[76,79]$ and has been employed for both biomedical and cultural heritage studies.

For the first part of the results, a multi-layered sample that simulates a painted artwork was created. It contained a layer of paint (red lead mixed with linseed oil) and a layer of varnish (dammar dissolved in dichloromethane) on top of it. For the aging measurements (second part), two different varnishes were tested. For the solution preparation of the varnishes, dammar was dissolved in dichloromethane and colophony in white spirit. All the solutions were cast on thin glass coverslips and they were left to dry in atmospheric conditions in order to form solid thin films of even thickness. The samples were artificially aged under low-pressure mercury discharged lamps.

\section{Results and Discussion}

In our previous works $[75,76]$, the applications of non-linear imaging techniques as diagnostic tools to $\mathrm{CH}$ studies were presented. In the current study, we have introduced an overview of the main optical- and laser-based diagnostic methods, such as LIBS, LIF, Raman, OCT, FTIR etc., in the service of $\mathrm{CH}$. Furthermore, except for the analytical presentation of the non-linear techniques, the synergy of these techniques with other well-established imaging modalities as diagnostic tools for $\mathrm{CH}$ studies has also been demonstrated. One critical aspect in the study of $\mathrm{CH}$ objects is the portability of the employed equipment. In the current work, the construction of a novel, fully transportable system that combines different non-linear techniques for real case applications is discussed and analyzed. The technical details, as well as all the necessary requirements, are thoroughly described. This information comprises the initial crucial step for the development of a fully portable workstation.

\subsection{Layer Discrimination in Multi-layered Samples}

In the first case, the potential of MFEF measurements to distinguish the different layers of model painted artworks has been investigated. The non-linear measurements on this double layer sample reveal the MPEF capability to distinguish the pigment (green/red) from the varnish (blue) layer due to the different fluorescent emission levels, as shown in Figure 2.

The sample was irradiated with tightly focused fs pulses located in the near-infrared region of the spectrum $(1030 \mathrm{~nm})$. The investigated fresh varnish presented high transparency in the visible and infrared regions of the spectrum, while it absorbed strongly in the near UV part, thus demonstrating a predominant three-photon excitation mechanism for the employed excitation wavelength. On the other hand, the underlying paint layer presented strong two and one photon absorption properties. A low intensity MPEF arose from the layer of dammar, while the painting layer emitted a higher intensity fluorescence signal, as shown in Figure 2. Analysis and discrimination of the recorded MPEF for the precise layer thickness detection was achieved through the use of an image processing algorithm in the MATLAB programming environment [118]. The thickness of the dammar varnish was $82 \mu \mathrm{m}$ and the thickness of the red led paint layer was $98 \mu \mathrm{m}$. The precise definition of varnish thickness was accomplished due to the transparency of the dammar varnish in the employed excitation wavelength. Information about the maximum penetration depth, rather than the thickness of the pigment layer, was obtained due to the high absorption and scattering of the NIR excitation wavelength from the paint layer. It is worth mentioning that the resulting depth values were corrected for apparent depth distortion due to the refractive index mismatch between air and the measured layers.

The MPEF measurements performed in the reflection mode and the results of the multi-layered model painted sample presented here, prove that it is possible to acquire in-depth information and discriminate the varnish protective layers from the painting substrate based on the intensity levels of the detected fluorescence signals. 


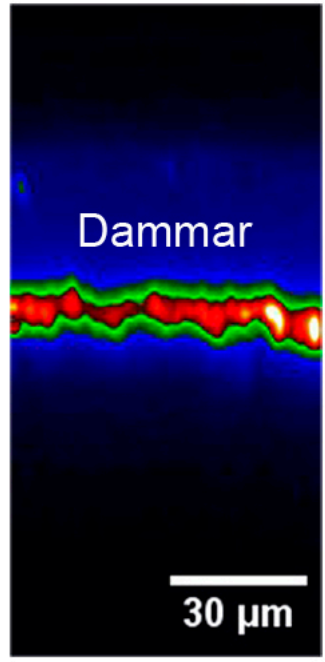

(a)

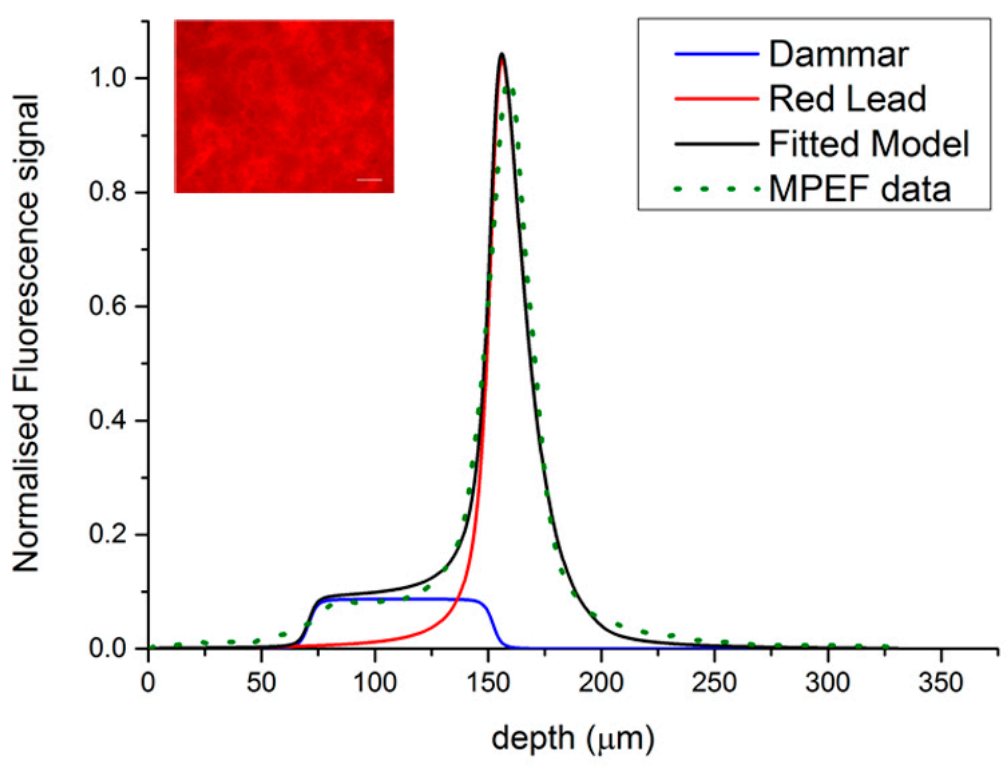

(b)

Figure 2. (a) Multi-Photon Excitation Fluorescence (MPEF) cross-sectional imaging of a model multi-layer sample contains a layer of red lead (red/green) and a layer of dammar (blue). (b) MPEF signal deconvolution in a z-scan plot profile. The fitted model (black line, $\mathrm{R}^{2}=0.99$ ) was used to decouple the recorded response (green points) into respective signal contributions arising from dammar (blue line) and red lead (red line). The multi-layer sample was casted on a thin round glass slide. Inset: White light optical longitudinal image $(x-y)$ of the irradiated region. Scale bar $20 \mu \mathrm{m}$.

\subsection{Artificial Aging Studies}

The progressive deterioration of the outer protective layers of the original painted artworks due to aging is a crucial problem with high significance for conservation scientists. In this series of measurements, the use of non-linear methods as an analytical diagnostic tool for the elucidation of this essential problem of aging is described. It is shown that, while THG measurements identified the thickness of the different layers through the simultaneous performance of MPEF imaging, it is feasible to obtain information related to the precise assessment of the degradation of two artificially aged natural varnishes as a function of depth. The triterpenoid varnish of dammar and the diterpenoid varnish of colophony/rosin were tested. The most frequently used natural resin varnishes consist of dammar due to its excellent adhesive properties, good solubility in solvents, and because it yellows to a lesser extent than other varnishes [122]. Colophony has been used in many coating applications, such as adhesives, varnishes, and inks, because of fast drying properties, excellent solubility, and compatibility with other resins and oils, and ready availability. Fresh and artificially aged varnish samples were examined via non-linear imaging measurements.

The employed non-linear imaging microscopy techniques provide, except from thickness determination of the different layers, in-depth unique information related to the estimation of the threshold for the degradation procedure due to aging effects of the varnish protective layers, as shown in Figures 3 and 4. Such information could assist any restoration process and makes possible the implementation of this non-destructive technique for real case studies, such as the removal of the aged varnish layers of original painted artworks. 


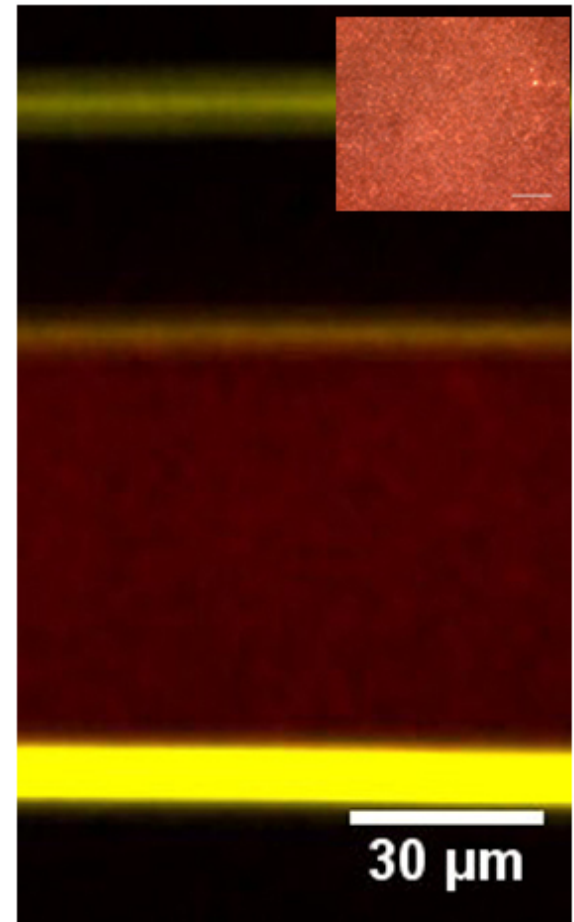

(a)

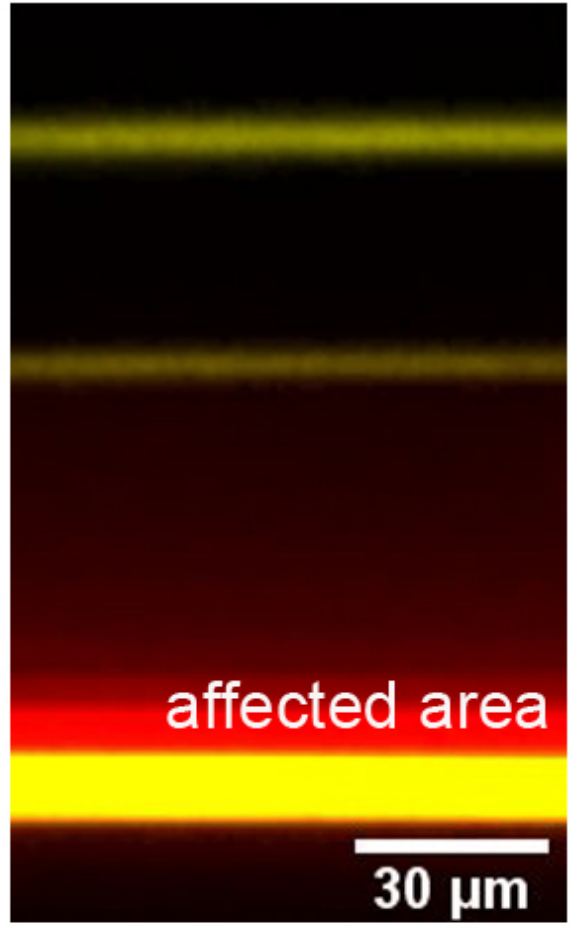

(b)

Figure 3. Multimodal cross-sectional non-linear imaging of fresh (a) and aged (b) dammar varnish sample (third harmonic generation (THG) in yellow, MPEF in red). High THG signals arise from interfaces. The upper one corresponds to the air/glass interface and the lower one to the dammar/air interface. The middle layer represents the glass/dammar interface. MPEF measurements provide essential in-depth information related to the affected region of the dammar due to artificial aging (b). The artificially aged sample emits a higher intensity fluorescence signal from the surface till a certain depth that indicates the main affected region due to the aging procedure. The increase of the fluorescence signal from the aged sample is probably due to the alteration in the optical properties of the outer layers of the aged varnish. The thickness of dammar was $158 \mu \mathrm{m}$, while the affected region due to aging measured $23 \mu \mathrm{m}$. Inset: White light optical longitudinal image $(x-y)$ of the fresh region. Scale bar $20 \mu \mathrm{m}$.

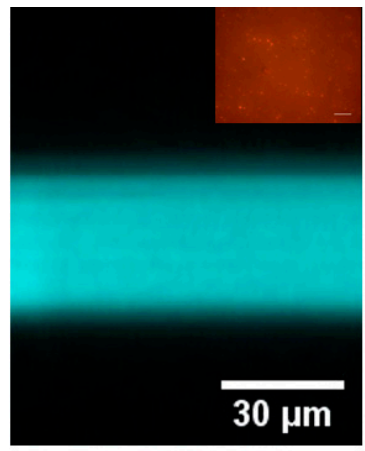

(a)

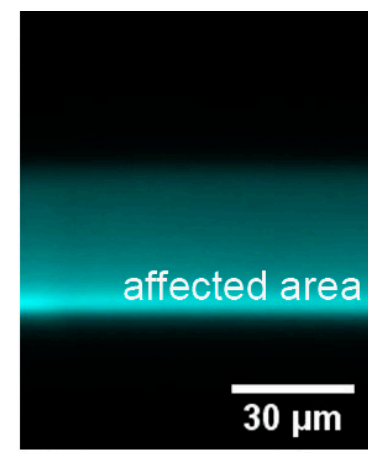

(b)

Figure 4. Cross-sectional MPEF imaging of (a) fresh and (b) aged colophony sample. MPEF signals arise from the layer of colophony, confirming the thickness of the sample. The thickness of colophony is in the order of $78 \mu \mathrm{m}$. The thickness of the main affected region $(\mathbf{b})$ is measured and found to be $\sim 18$ $\mu \mathrm{m}$, based on the higher fluorescence signal recorded from the aged colophony sample. Inset: White light optical longitudinal image (x-y) of the fresh region. Scale bar $20 \mu \mathrm{m}$. 


\subsection{Towards the Construction of a Transportable System for in situ Applications}

Following the optimization and validation of the various non-linear optical imaging modalities performed in the laboratory on model samples and real $\mathrm{CH}$ objects [76,82], the general application of these techniques for in situ studies of $\mathrm{CH}$ objects and substrates will require the development of a transportable prototype system. At first, the construction of a transportable system for the investigation of various $\mathrm{CH}$ objects in controlled indoor environments, such as museums and galleries, is required. The application of such an innovative system under established conditions will provide all the necessary feedback to determine the advantages and limitations of the non-linear optical microscope for non-invasive, in situ measurements of real $\mathrm{CH}$ objects. As a second step, the accumulated knowledge and experience by the development of the transportable set-up will contribute to the design and manufacturing of a fully mobile, user-friendly system for performing in-situ measurements outdoors, i.e., archaeological sites and excavation areas.

The transportable system will consist of a non-linear, custom made upright optical microscope coupled with a compact, stable, sealed, air cooled ultrafast femtosecond (fs) laser source. Appropriate laser sources have advanced technically, while they have dramatically dropped in cost [123] over the last years. For real applications the reflection mode of operation is a prerequisite. The non-linear modalities of SHG and MPEF are usually applied in the reflection mode and it has been demonstrated that the modality of THG is also feasible in this mode of operation [124]. The use of a spectrally tunable laser source will increase the system capabilities enormously by ensuring the best possible transmission of laser light on a wider range of materials. The system will also incorporate capabilities for the detection of very weak signals. Thus, special schemes can be employed to provide amplification of the recorded signals, to reject noise, and to contribute to the measurements in less stringent lighting conditions (e.g., using lock-in detection). The schematic set-up is presented in Figure 5.

The development of a user-friendly, transportable non-linear optical microscope that can be used by conservation scientists is challenging. However, all of the miniaturization technologies needed for such a device are being developed for biomedical applications and can be adapted to the peculiarities of $\mathrm{CH}$ and artwork studies.

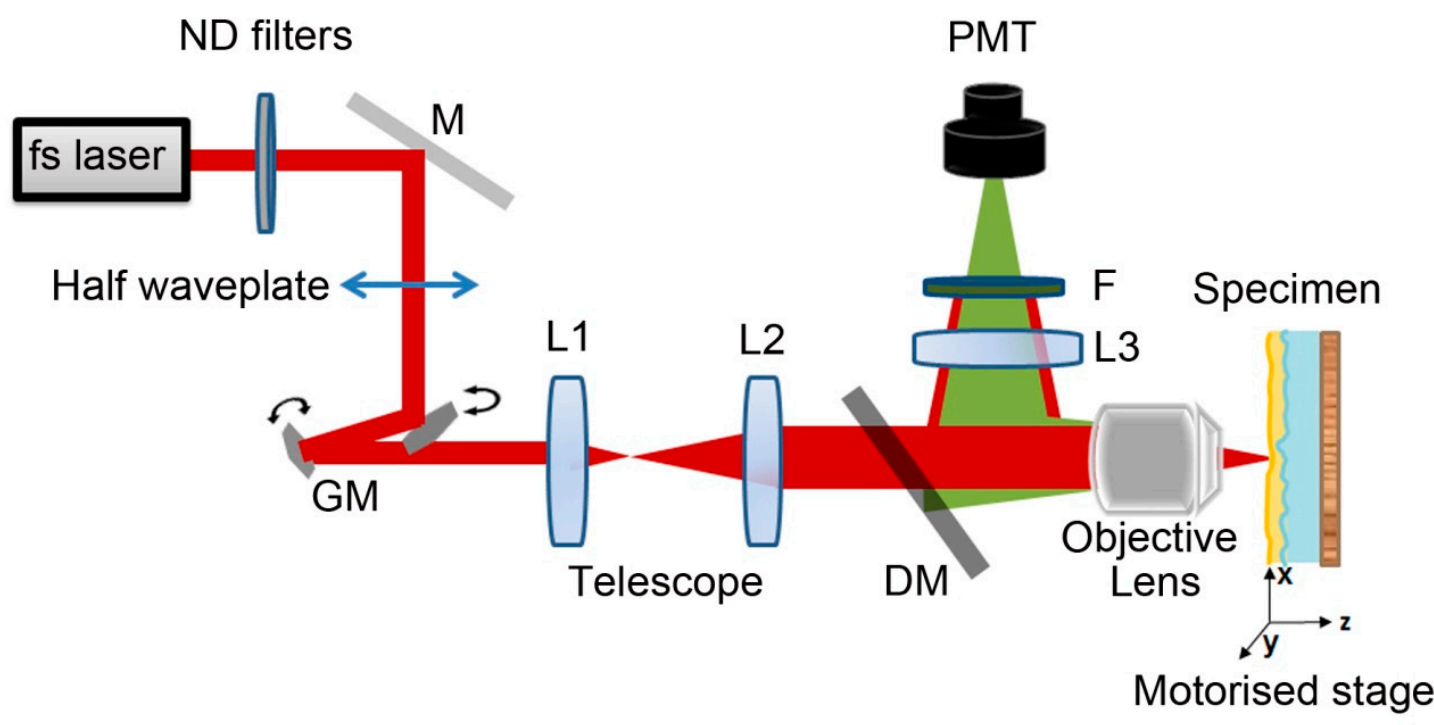

Figure 5. Scheme for a transportable non-linear optical system. Fs: femtosecond laser, ND: neutral density filters, M: mirror, GM: galvanometric mirrors, DM: dichroic mirror, L: lens, F: optical filter, PMT: photomultiplier tube, $\mathrm{L}_{1}-\mathrm{L}_{2}$ : telescope system. The specimen is placed on an $\mathrm{XYZ}$ motorized translational stage. 


\subsection{Microscope Specifications}

The microscope module should include a custom made modified upright microscope, an XYZ high-precision scanning stage for positioning the sample, detection units (photomultipliers), proper spectral filters, a charged coupled device (CCD) camera for direct observation of the object, high numerical aperture (N.A.) objective lenses, and a lock-in amplifier.

Adjustable neutral density filters are required to precisely control the laser power at the sample plane. A telescope system, which expands the laser beam, can be used to fill the back aperture (entrance pupil) of the objective lens. High numerical aperture (N.A. $>0.75$ ) objective lenses have to be employed to achieve tight focusing of the laser beam onto the sample. A half wave plate can be used to control and rotate the orientation of the linear polarization of the excitation laser. Controlled scanning will be performed by movement of the sample placed on a motorized XYZ translation stage with micrometric resolution. Non-linear signals will be collected in the backward direction using a photomultiplier tube (PMT). The adequate filters will be placed in front of the PMT to cut off the reflected laser light and solely detect the desired non-linear signals arising from the samples. A CCD camera will be employed for observation of the specimens. A lock-in amplifier will be also used for good noise rejection and for performing measurements in less stringent lighting conditions. The LabVIEW interface will control both scanning and data acquisition procedures.

\section{Conclusions}

Non-linear optical microscopy techniques have been at the forefront of biomedical research over the last decades and only recently have they been used as diagnostic and characterization tools for $\mathrm{CH}$ studies. Thus far, these techniques have provided interesting results with regard to accurately control any cleaning interventions in artworks. Non-linear microscopy modalities provide new insights for the assessment of the appropriate conservation method that has to be followed for various $\mathrm{CH}$ objects of high significance. Multi-photon microscopes are now commercially available and include flexible and easy to use, single femtosecond laser beam systems. It is anticipated that the construction of a state-of-the-art transportable non-linear workstation prototype will significantly improve the restoration outcome of various $\mathrm{CH}$ objects. The current study describes analytically the construction of an innovative transportable non-linear optical system and its technical requirements. This information can be used as a base for the future design and manufacture of a user-friendly and transportable non-linear system for in situ $\mathrm{CH}$ studies. A developed compact, non-linear optical microscope prototype will be extensively used by $\mathrm{CH}$ scientists in museums and galleries and it will provide the necessary feedback for the construction of a fully mobile system to perform in situ measurements outdoors. Furthermore, this prototype workstation can be used in combination with other non-invasive portable imaging techniques (e.g., optical coherence tomography) in order to achieve complementary information from multi-layered $\mathrm{CH}$ objects and substrates.

Author Contributions: In the present study, M.M. was the person in charge for the performance of all the experiments and data analysis. G.F. conceived and supervised the project. M.M. and G.F. wrote the paper. All authors have read and agreed to the published version of the manuscript.

Funding: This work is supported by the project "BIOIMAGING" (MIS 5002755), which is implemented under the "Action for Strengthening Research and Innovation Infrastructures", funded by the Operational Programme "Competitiveness, Entrepreneurship and Innovation" (NSRF 2014-2020) and co-financed by Greece and the European Union (European Regional Development Fund). MM also acknowledges the Hellenic Foundation for Research and Innovation (HFRI) and the General Secretariat for Research and Technology (GSRT), for the financial support under grant agreement No [1357].

Acknowledgments: The authors would like to thank V. Tsafas for the algorithm construction and the fitted model curve on our MPEF data and K. Melessanaki for her assistance in the preparation of the samples.

Conflicts of Interest: The authors declare no conflict of interest. 


\section{References}

1. Carlyle, L. The Artist's Assistant, Oil Painting Instruction Manuals and Handbooks in Britain 1800-1900 with Reference to Selected Eighteenth-Century Sources; Archetype Publications Ltd.: London, UK, 2001.

2. Eastaugh, N.; Walsh, V.; Siddall, R.; Chaplin, T. Optical Microscopy of Historical Pigments; The Pigment Compendium: London, UK, 2004.

3. Stoner, J.H.; Rushfield, R.A. Conservation of Easel Paintings; Routledge: London, UK, 2012.

4. Miliani, C.; Monico, L.; Melo, M.J.; Fantacci, S.; Angelin, E.M.; Romani, A.; Janssens, K. Photochemistry of Artists' Dyes and Pigments: Towards Better Understanding and Prevention of Colour Change in Works of Art. Angew. Chem. Int. Ed. 2018, 57, 7324-7334. [CrossRef] [PubMed]

5. Area, M.C.; Cheradame, H. Paper aging and degradation: Recent findings and research methods. BioResources 2011, 6, 5307-5337.

6. Kuchitsu, N.; Morii, M.; Sakai, S.; Unten, H. Simple evaluation of the degradation state of cultural heritage based on multi-view stereo. Prog. Earth Planet. Sci. 2019, 6, 12. [CrossRef]

7. Palomar, T.; Oujja, M.; Castillejo, M.; Sabio, R.; Rincón, J.; García-Heras, M.; Villegas, M. Roman glasses from Augusta Emerita: Study of degradation pathologies using LIBS. In Sciene and Technology for the Conservation of Cultural Heritage; CRC Press: London, UK, 2013; pp. 251-256.

8. Melcher, M.; Wiesinger, R.; Schreiner, M. Degradation of Glass Artifacts: Application of Modern Surface Analytical Techniques. Accounts Chem. Res. 2010, 43, 916-926. [CrossRef]

9. Gelbrich, J.; Mai, C.; Militz, H. Evaluation of bacterial wood degradation by Fourier Transform Infrared (FTIR) measurements. J. Cult. Heritage 2012, 13, S135-S138. [CrossRef]

10. Dinnebier, R.E.; Runčevski, T.; Fischer, A.; Eggert, G. Solid-State Structure of a Degradation Product Frequently Observed on Historic Metal Objects. Inorg. Chem. 2015, 54, 2638-2642. [CrossRef]

11. Hwang, S.; Song, H.; Cho, S.W.; Kim, C.E.; Kim, C.S.; Kim, K. Optical Measurements of Paintings and the Creation of an Artwork Database for Authenticity. PLoS ONE 2017, 12, e0171354. [CrossRef]

12. Pouli, P.; Selimis, A.; Georgiou, S.; Fotakis, C. Recent Studies of Laser Science in Paintings Conservation and Research. Accounts Chem. Res. 2010, 43, 771-781. [CrossRef]

13. Anglos, D. Laser-induced breakdown spectroscopy in heritage science. Phys. Sci. Rev. 2019, 4. [CrossRef]

14. Botto, A.; Campanella, B.; Legnaioli, S.; Lezzerini, M.; Lorenzetti, G.; Pagnotta, S.; Poggialini, F.; Palleschi, V. Applications of laser-induced breakdown spectroscopy in cultural heritage and archaeology: A critical review. J. Anal. At. Spectrom. 2019, 34, 81-103. [CrossRef]

15. Anglos, D.; Detalle, V. Cultural Heritage Applications of LIBS. Springer Ser. Opt. Sci. 2014, 182, 531-554.

16. Osticioli, I.; Agresti, J.; Fornacelli, C.; Memmi, I.T.; Siano, S. Potential role of LIPS elemental depth profiling in authentication studies of unglazed earthenware artifacts. J. Anal. At. Spectrom. 2012, 27, 827. [CrossRef]

17. Gaudiuso, R.; Dell'Aglio, M.; De Pascale, O.; Senesi, G.S.; De Giacomo, A. Laser Induced Breakdown Spectroscopy for Elemental Analysis in Environmental, Cultural Heritage and Space Applications: A Review of Methods and Results. Sensors 2010, 10, 7434-7468. [CrossRef] [PubMed]

18. Papliaka, Z.E.; Philippidis, A.; Siozos, P.; Vakondiou, M.; Melessanaki, K.; Anglos, D. A multi-technique approach, based on mobile/portable laser instruments, for the in situ pigment characterization of stone sculptures on the island of Crete dating from Venetian and Ottoman period. Heritage Sci. 2016, 4, 728. [CrossRef]

19. Westlake, P.; Siozos, P.; Philippidis, A.; Apostolaki, C.; Derham, B.; Terlixi, A.; Perdikatsis, V.; Jones, R.; Anglos, D. Studying Pigments on Painted Plaster in Minoan, Roman and Early Byzantine Crete. A Multi-Analytical Technique Approach. Anal. Bioanal. Chem. 2012, 402, 1413-1432. [CrossRef] [PubMed]

20. Kosma, K.; Andrianakis, M.; Hatzigiannakis, K.; Tornari, V. Digital holographic interferometry for cultural heritage structural diagnostics: A coherent and a low-coherence optical set-up for the study of a marquetry sample. Strain 2018, 54, e12263. [CrossRef]

21. Kang, H.; Stoykova, E.; Berberova, N.; Park, J.; Nazarova, D.; Park, J.S.; Kim, Y.; Hong, S.; Ivanov, B.; Malinowski, N. Three-dimensional imaging of cultural heritage artifacts with holographic printers. In Proceedings of the 19th International Conference and School on Quantum Electronics: Laser Physics and Applications, Sozopol, Bulgaria, 5 January 2017; Volume 10226, p. 102261.

22. Kim, S.J.; Deng, F.; Brown, M.S. Visual enhancement of old documents with hyperspectral imaging. Pattern Recognit. 2011, 44, 1461-1469. [CrossRef] 
23. Hedjam, R.; Cheriet, M. Historical document image restoration using multispectral imaging system. Pattern Recognit. 2013, 46, 2297-2312. [CrossRef]

24. Liang, H. Advances in Multispectral and Hyperspectral Imaging for Archaeology and Art Conservation. Appl. Phys. A 2012, 106, 309-323. [CrossRef]

25. Kogou, S.; Neate, S.; Coveney, C.; Miles, A.; Boocock, D.; Burgio, L.; Cheung, C.S.; Liang, H. The origins of the Selden map of China: Scientific analysis of the painting materials and techniques using a holistic approach. Heritage Sci. 2016, 4, 37. [CrossRef]

26. Delaney, J.K.; Picollo, M. JAIC special issue on "Reflectance hyperspectral imaging to support documentation and conservation of 2D artworks". J. Am. Inst. Conserv. 2019, 58,1-2. [CrossRef]

27. Anglos, D. Shedding light on the past: Optical technologies applied to cultural heritage. Heritage Sci. $2017,5$. [CrossRef]

28. Nevin, A.; Spoto, G.; Anglos, D. Laser Spectroscopies for Elemental and Molecular Analysis in Art and Archaeology. Appl. Phys. A 2012, 106, 339-361. [CrossRef]

29. Ricciardi, P.; Colomban, P.; Tournié, A.; Milande, V. Nondestructive on-site identification of ancient glasses: Genuine artefacts, embellished pieces or forgeries? J. Raman Spectrosc. 2009, 40, 604-617. [CrossRef]

30. Caggiani, M.C.; Colomban, P. Testing of Raman spectroscopy as a non-invasive tool for the investigation of glass-protected pastels. J. Raman Spectrosc. 2011, 42, 790-798. [CrossRef]

31. Colomban, P.; Tournié, A. On-site Raman identification and dating of ancient/modern stained glasses at the Sainte-Chapelle, Paris. J. Cult. Heritage 2007, 8, 242-256. [CrossRef]

32. Badea, G.I.; Caggiani, M.C.; Colomban, P.; Mangone, A.; Teodor, E.D.; Teodor, E.S.; Radu, G.-L. Fourier Transform Raman and Statistical Analysis of Thermally Altered Samples of Amber. Appl. Spectrosc. 2015, 69, 1457-1463. [CrossRef]

33. Peets, P.; Leito, I.; Pelt, J.; Vahur, S. Identification and classification of textile fibres using ATR-FT-IR spectroscopy with chemometric methods. Spectrochim. Acta Part A Mol. Biomol. Spectrosc. 2017, 173, $175-181$. [CrossRef]

34. Ion, R.M.; Boros, D.; Ion, M.L.; Dumitriu, I.; Fierascii, R.C.; Radovici, C.; Florea, G.; Bercu, C. Combined spectral analysis (EDXRF, ICP-AES, XRD, FTIR) for characterization of bronze roman mirror. Met. Int. 2008, 13, 61-65.

35. Fierascu, R.C.; Avramescu, S.M.; Vasilievici, G.; Fierascu, I.; Paunescu, A. Thermal and spectroscopic investigation of Romanian historical documents from the nineteenth and twentieth century. J. Therm. Anal. Calorim. 2016, 123, 1309-1318. [CrossRef]

36. Akyuz, T.; Akyuz, S.; Balci, K.; Gulec, A. Investigations of historical textiles from the Imperial Pavilion (Hunkar Kasri) of the new mosque Eminonu-Istanbul (Turkey) by multiple analytical techniques. J. Cult. Heritage 2017, 25, 180-184. [CrossRef]

37. Higgitt, C.; Harris, S.; Cartwright, C.; Cruickshank, P. Assessing the potential of historic archaeological collections: A pilot study of the British Museum's Swiss lake dwelling textiles. Br. Museum Techn. Res. Bull. 2011, 5, 81-94.

38. La Russa, M.F.; Ruffolo, S.A.; Barone, G.; Crisci, G.M.; Mazzoleni, P.; Pezzino, A. The Use of FTIR and Micro-FTIR Spectroscopy: An Example of Application to Cultural Heritage. Int. J. Spectrosc. 2009, 2009, 1-5. [CrossRef]

39. Miliani, C.; Rosi, F.; Daveri, A.; Brunetti, B.G. Reflection infrared spectroscopy for the non-invasive in situ study of artists' pigments. App. Phys. A Mater. 2012, 106, 295-307. [CrossRef]

40. Bell, J.; Nel, P.; Stuart, B. Non-invasive identification of polymers in cultural heritage collections: Evaluation, optimisation and application of portable FTIR (ATR and external reflectance) spectroscopy to three-dimensional polymer-based objects. Heritage Sci. 2019, 7, 1-18. [CrossRef]

41. Yan, Y.; Wen, C.; Jin, M.; Duan, L.; Zhang, R.; Luo, C.; Xiao, J.; Ye, Z.; Gao, B.; Liu, P.; et al. FTIR Spectroscopy in Cultural Heritage Studies: Non-destructive Analysis of Chinese Handmade Papers. Chem. Res. Chin. Univ. 2019, 35, 586-591. [CrossRef]

42. Liang, H.; Cid, M.G.; Cucu, R.G.; Dobre, G.M.; Podoleanu, A.G.; Pedro, J.; Saunders, D. En-face optical coherence tomography-A novel application of non-invasive imaging to art conservation. Opt. Express 2005, 13, 6133. [CrossRef]

43. Arecchi, T.; Bellini, M.; Corsi, C.; Fontana, R.; Materazzi, M.; Pezzati, L.; Tortora, A. A new tool for painting diagnostics: Optical coherence tomography. Opt. Spectrosc. 2006, 101, 23-26. [CrossRef] 
44. Liang, H.; Peric, B.; Hughes, M.; Podoleanu, A.G.; Spring, M.; Roehrs, S. Optical Coherence Tomography in archaeological and conservation science-A new emerging field. In Proceedings of the 1st Canterbury Workshop and School in Optical Coherence Tomography and Adaptive Optics, Canterbury, UK, 30 December 2008.

45. Targowski, P.; Iwanicka, M. Optical Coherence Tomography: Its Role in the Non-Invasive Structural Examination and Conservation of Cultural Heritage Objects-A Review. App. Phys. A Mater. 2012, 106, 265-277. [CrossRef]

46. Striova, J.; Fontana, R.; Barucci, M.; Felici, A.; Marconi, E.; Pampaloni, E.; Raffaelli, M.; Riminesi, C. Optical devices provide unprecedented insights into the laser cleaning of calcium oxalate layers. Microchem. J. 2016, 124, 331-337. [CrossRef]

47. Iwanicka, M.; Tymińska-Widmer, L.; Rouba, B.J.; Kwiatkowska, E.A.; Sylwestrzak, M.; Targowski, P. Through-Glass Structural Examination of Hinterglasmalerei by Optical Coherence Tomography. In Lasers in the Conservation of Artworks VIII-Proceedings of the International Conference on Lasers in the Conservation of Artworks VIII, LACONA VIII; CRC Press: Sibiu, Romania, 2011; pp. 209-214.

48. Kunicki-Goldfinger, J.; Targowski, P.; Góra, M.; Karaszkiewicz, P.; Dzierżanowski, P. Characterization of Glass Surface Morphology by Optical Coherence Tomography. Stud. Conserv. 2009, 54, 117-128. [CrossRef]

49. Yang, M.-L.; Winkler, A.; Klein, J.; Wall, A.; Barto, J. Using Optical Coherence Tomography to Characterize the Crack Morphology of Ceramic Glaze and Jade. In Selected Topics in Optical Coherence Tomography; IntechOpen: Shanghai, China, 2012.

50. Iwanicka, M.; Kwiatkowska, E.A.; Sylwestrzak, M.; Targowski, P. Application of optical coherence tomography (OCT) for real time monitoring of consolidation of the paint layer in Hinterglasmalerei objects. SPIE Opt. Metrol. 2011, 8084, 80840.

51. Liang, H.; Lange, R.; Peric, B.; Spring, M. Optimum spectral window for imaging of art with optical coherence tomography. Appl. Phys. A 2013, 111, 589-602. [CrossRef]

52. Flammini, M.; Bonsi, C.; Ciano, C.; Giliberti, V.; Pontecorvo, E.; Italia, P.; DelRe, E.; Ortolani, M. Confocal Terahertz Imaging of Ancient Manuscripts. J. Infrared Millim. Terahertz Waves 2017, 38, 435-442. [CrossRef]

53. Catapano, I.; Soldovieri, F. A Data Processing Chain for Terahertz Imaging and Its Use in Artwork Diagnostics. J. Infrared Millim. Terahertz Waves 2017, 38, 518-530. [CrossRef]

54. Cosentino, A. Terahertz and Cultural Heritage Science: Examination of Art and Archaeology. Technologies 2016, 4, 6. [CrossRef]

55. Öhrström, L.; Fischer, B.M.; Bitzer, A.; Wallauer, J.; Walther, M.; Rühli, F. Terahertz Imaging Modalities of Ancient Egyptian Mummified Objects and of a Naturally Mummified Rat. Anat. Rec. Adv. Integr. Anat. Evol. Boil. 2015, 298, 1135-1143. [CrossRef]

56. Jackson, J.B.; Mourou, M.; Whitaker, J.; Duling, I.; Williamson, S.; Menu, M.; Mourou, G.; Iii, I.D. Terahertz imaging for non-destructive evaluation of mural paintings. Opt. Commun. 2008, 281, 527-532. [CrossRef]

57. Fukunaga, K. Case Studies of THz Pulsed TDI. In Metallography in Archaeology and Art; Springer Science and Business Media LLC: Berlin/Heidelberg, Germany, 2016; Volume 4, pp. 85-144.

58. Dandolo, C.L.K.; Jepsen, P.U.; Christensen, M.C. Characterization of European lacquers by terahertz (THz) reflectometric imaging. In Proceedings of the 2013 Digital Heritage International Congress (DigitalHeritage), Marseille, France, 28 October-1 November 2013.

59. Skryl, A.S.; Jackson, J.B.; Bakunov, M.I.; Menu, M.; Mourou, G.A. Terahertz time-domain imaging of hidden defects in wooden artworks: Application to a Russian icon painting. Appl. Opt. 2014, 53, 1033-1038. [CrossRef]

60. Abraham, E.; Fukunaga, K. Terahertz Imaging Applied to the Examination of Artistic Objects. Stud. Conserv. 2015, 60, 343-352. [CrossRef]

61. Seco-Martorell, C.; López-Domínguez, V.; Arauz-Garofalo, G.; Redo-Sanchez, A.; Palacios, J.; Tejada, J. Goya's artwork imaging with Terahertz waves. Opt. Express 2013, 21, 17800. [CrossRef] [PubMed]

62. Grönlund; Johansson, A.; Barup, K.; Svanberg, S. Hällström Remote Multicolor Excitation Laser-Induced Fluorescence Imaging. Laser Chem. 2006, 2006, 1-6.

63. Fantoni, R.; Caneve, L.; Colao, F.; Fiorani, L.; Palucci, A.; Dell'Erba, R.; Fassina, V. Laser-induced fluorescence study of medieval frescoes by Giusto de' Menabuoi. J. Cult. Heritage 2013, 14, S59-S65. [CrossRef] 
64. Martínez-Hernández, A.; Oujja, M.; Sanz, M.; Carrasco, E.; Detalle, V.; Castillejo, M. Analysis of heritage stones and model wall paintings by pulsed laser excitation of Raman, laser-induced fluorescence and laser-induced breakdown spectroscopy signals with a hybrid system. J. Cult. Heritage 2018, 32, 1-8. [CrossRef]

65. Tserevelakis, G.J.; Fovo, A.D.; Melessanaki, K.; Fontana, R.; Zacharakis, G. Photoacoustic signal attenuation analysis for the assessment of thin layers thickness in paintings. J. Appl. Phys. 2018, 123, 123102. [CrossRef]

66. Tserevelakis, G.J.; Vrouvaki, I.; Siozos, P.; Melessanaki, K.; Hatzigiannakis, K.; Fotakis, C.; Zacharakis, G. Photoacoustic imaging reveals hidden underdrawings in paintings. Sci. Rep. 2017, 7, 747. [CrossRef]

67. Tserevelakis, G.J.; Pozo-Antonio, J.S.; Siozos, P.; Rivas, T.; Pouli, P.; Zacharakis, G. On-line photoacoustic monitoring of laser cleaning on stone: Evaluation of cleaning effectiveness and detection of potential damage to the substrate. J. Cult. Heritage 2019, 35, 108-115. [CrossRef]

68. Warren, W.S.; Fischer, M.C.; Tong, Y. Novel Nonlinear Contrast Improves Deep-Tissue Microscopy. Laser Focus World. 2007, 43, 99-103.

69. Ye, T.; Fu, D.; Warren, W.S. Nonlinear Absorption Microscopy. Photochem. Photobiol. 2009, 85, $631-645$. [CrossRef]

70. Samineni, P.; DeCruz, A.; Villafaña, T.E.; Warren, W.S.; Fischer, M.C. Pump-probe imaging of historical pigments used in paintings. Opt. Lett. 2012, 37, 1310-1312. [CrossRef]

71. Villafana, T.E.; Brown, W.P.; Delaney, J.K.; Palmer, M.; Warren, W.S.; Fischer, M.C. Femtosecond pump-probe microscopy generates virtual cross-sections in historic artwork. Proc. Natl. Acad. Sci. USA 2014, 111, 1708-1713. [CrossRef] [PubMed]

72. Yu, J.; Warren, W.S.; Fischer, M.C. Spectroscopic Differentiation and Microscopic Imaging of Red Organic Pigments Using Optical Pump-Probe Contrast. Anal. Chem. 2018, 90, 12686-12691. [CrossRef] [PubMed]

73. Stentz, A.J.; Boyd, R.W. Nonlinear optics. In The Handbook of Photonics, 2nd ed.; CRC Press: Boca Raton, FL, USA, 2006.

74. Stockert, J.C.; Blazquez-Castro, A.; Stockert, J.C.; Blazquez-Castro, A. Non-linear Optics. In Fluorescence Microscopy in Life Sciences; Bentham Science Publishers: Sharjah, UAE, 2017; pp. 642-686.

75. Filippidis, G.; Tserevelakis, G.J.; Selimis, A.; Fotakis, C. Nonlinear Imaging Techniques as Non-Destructive, High-Resolution Diagnostic Tools for Cultural Heritage Studies. Appl. Phys. A 2015, 118, 417-423. [CrossRef]

76. Mari, M.; Tsafas, V.; Melessanaki, K.; Filippidis, G. Applications of non-linear imaging microscopy techniques to cultural heritage objects. Insight Non Destr. Test. Cond. Monit. 2018, 60, 663-669. [CrossRef]

77. Liang, H.; Mari, M.; Cheung, C.S.; Kogou, S.; Johnson, P.; Filippidis, G. Optical coherence tomography and non-linear microscopy for paintings-A study of the complementary capabilities and laser degradation effects. Opt. Express 2017, 25, 19640. [CrossRef]

78. Fovo, A.D.; Fontana, R.; Striová, J.; Pampaloni, E.; Barucci, M.; Raffaelli, M.; Mercatelli, R.; Pezzati, L.; Cicchi, R. Nonlinear optical imaging techniques (NLO) for painting investigation. In Proceedings of the LACONA XI Lasers in the Conservation of Artworks XI, 20-23 September 2016; NCU Press Torun: Krakow, Poland.

79. Filippidis, G.; Mari, M.; Kelegkouri, L.; Philippidis, A.; Selimis, A.; Melessanaki, K.; Sygletou, M.; Fotakis, C. Assessment of In-Depth Degradation of Artificially Aged Triterpenoid Paint Varnishes Using Nonlinear Microscopy Techniques. Microsc. Microanal. 2015, 21, 510-517. [CrossRef]

80. Filippidis, G.; Melessanaki, K.; Fotakis, C. Second and third harmonic generation measurements of glues used for lining textile supports of painted artworks. Anal. Bioanal. Chem. 2009, 395, 2161-2166. [CrossRef]

81. Psilodimitrakopoulos, S.; Gavgiotaki, E.; Melessanaki, K.; Tsafas, V.; Filippidis, G. Polarization Second Harmonic Generation Discriminates Between Fresh and Aged Starch-Based Adhesives Used in Cultural Heritage. Microsc. Microanal. 2016, 22, 1072-1083. [CrossRef]

82. Latour, G.; Echard, J.-P.; Didier, M.; Schanne-Klein, M.-C. In situ 3D characterization of historical coatings and wood using multimodal nonlinear optical microscopy. Opt. Express 2012, 20, 24623. [CrossRef]

83. Latour, G.; Robinet, L.; Dazzi, A.; Portier, F.; Deniset-Besseau, A.; Schanne-Klein, M.C. Correlative Nonlinear Optical Microscopy and Infrared Nanoscopy Reveals Collagen Degradation in Altered Parchments. Sci. Rep. 2016, 6, 26344. [CrossRef]

84. Faraldi, F.; Tserevelakis, G.J.; Filippidis, G.; Ingo, G.M.; Riccucci, C.; Fotakis, C. Multi photon excitation fluorescence imaging microscopy for the precise characterization of corrosion layers in silver-based artifacts. Appl. Phys. A 2013, 111, 177-181. [CrossRef] 
85. Chang, S.; Mao, Y.; Flueraru, C. Jade detection and analysis based on optical coherence tomography images. Opt. Eng. 2010, 49, 063602. [CrossRef]

86. Yang, M.-L.; Lu, C.-W.; Hsu, I.-J.; Yang, C.-C. The Use of Optical Coherence Tomography for Monitoring the Subsurface Morphologies of Archaic Jades. Archaeometry 2004, 46, 171-182. [CrossRef]

87. Yang, M.; Winkler, A.M.; Barton, J.K.; Vandiver, P.B. Using optical coherence tomography to examine the subsurface morphology of chinese glazes. Archaeometry 2009, 51, 808-821. [CrossRef]

88. Pircher, M.; Bajraszewski, T.; Strlic, M.; Kolar, J.; Hitzenberger, C.K.; Targowski, P. Optical Coherence Tomography for Examination of Parchment Degradation. Laser Chem. 2006, 2006, 1-6. [CrossRef]

89. Vazquez-Calvo, C.; Martínez-Ramírez, S.; De Buergo, M.A.; Fort, R. The Use of Portable Raman Spectroscopy to Identify Conservation Treatments Applied to Heritage Stone. Spectrosc. Lett. 2012, 45, 146-150. [CrossRef]

90. Culka, A.; Jehlička, J. Identification of gemstones using portable sequentially shifted excitation Raman spectrometer and RRUFF online database: A proof of concept study. Eur. Phys. J. Plus 2019, 134, 130. [CrossRef]

91. Gierlinger, N.; Schwanninger, M. Chemical Imaging of Poplar Wood Cell Walls by Confocal Raman Microscopy. Plant Physiol. 2006, 140, 1246-1254. [CrossRef]

92. Wei, D.; Chen, S.; Liu, Q. Review of Fluorescence Suppression Techniques in Raman Spectroscopy. Appl. Spectrosc. Rev. 2015, 50, 387-406. [CrossRef]

93. Ziemann, M.A. In situ micro-Raman spectroscopy on minerals on-site in the Grotto Hall of the New Palace, Park Sanssouci, in Potsdam. J. Raman Spectrosc. 2006, 37, 1019-1025. [CrossRef]

94. Jehlička, J.; Culka, A.; Bersani, D.; Vandenabeele, P. Comparison of seven portable Raman spectrometers: Beryl as a case study. J. Raman Spectrosc. 2017, 48, 1289-1299. [CrossRef]

95. Colomban, P.; Tournié, A.; Maucuer, M.; Meynard, P. On-Site Raman and XRF Analysis of Japanese/Chinese Bronze/brass Patina-The Search for Specific Raman Signatures. J. Raman Spectrosc. 2012, 43, 799-808. [CrossRef]

96. Asquier, M.; Colomban, P.; Milande, V. Raman and Infrared Analysis of Glues Used for Pottery Conservation Treatments. J. Raman Spectrosc. 2009, 40, 1641-1644. [CrossRef]

97. Daher, C.; Paris, C.; Le Hô, A.-S.; Bellot-Gurlet, L.; Echard, J.-P. A joint use of Raman and infrared spectroscopies for the identification of natural organic media used in ancient varnishes. J. Raman Spectrosc. 2010, 41, 1494-1499. [CrossRef]

98. Castro, K.; Pessanha, S.; Proietti, N.; Princi, E.; Capitani, D.; Carvalho, M.L.; Madariaga, J.M. Noninvasive and nondestructive NMR, Raman and XRF analysis of a Blaeu coloured map from the seventeenth century. Anal. Bioanal. Chem. 2008, 391, 433-441. [CrossRef] [PubMed]

99. Mannucci, E.; Pastorelli, R.; Zerbi, G.; Bottani, C.E.; Facchini, A. Recovery of ancient parchment: Characterization by vibrational spectroscopy. J. Raman Spectrosc. 2000, 31, 1089-1097. [CrossRef]

100. Tserevelakis, G.J.; Tsagkaraki, M.; Siozos, P.; Zacharakis, G. Uncovering the Hidden Content of Layered Documents by Means of Photoacoustic Imaging. Strain 2019, 55, e12289. [CrossRef]

101. Manfredi, A.; Barberis, L.; Bearman, R.; Marengo, M. Portable non-invasive imaging method for monitoring the conservation of frescoes. 2015 Digital Heritage 2015, 2, 449-452.

102. Salerno, E.; Tonazzini, A.; Grifoni, E.; Lorenzetti, G.; Legnaioli, S.; Lezzerini, M.; Marras, L.; Pagnotta, S.; Palleschi, V. Analysis of Multispectral Images in Cultural Heritage and Archaeology. J. Laser Appl. Spectrosc. 2014, 1, 22-27.

103. Pouli, P.; Zafiropulos, V.; Balas, C.; Doganis, Y.; Galanos, A. Laser cleaning of inorganic encrustation on excavated objects: Evaluation of the cleaning result by means of multi-spectral imaging. J. Cult. Heritage 2003, 4, 338-342. [CrossRef]

104. Papadakis, V.; Loukaiti, A.; Pouli, P. A spectral imaging methodology for determining on-line the optimum cleaning level of stonework. J. Cult. Heritage 2010, 11, 325-328. [CrossRef]

105. Cavaleri, T.; Buscaglia, P.; Migliorini, S.; Nervo, M.; Piccablotto, G.; Piccirillo, A.; Pisani, M.; Puglisi, D.; Vaudan, D.; Zucco, M. Pictorial Materials Database: 1200 Combinations of Pigments, Dyes, Binders and Varnishes Designed as a Tool for Heritage Science and Conservation. Appl. Phys. A 2017, 123, 419. [CrossRef]

106. Hoyer, T.; Löffler, T.; Saito, T.; Yukihira, N.; Deninger, A.; Fukunaga, K. A portable all-electronic THz scanner for the inspection of structural earthquake damage in Japanese buildings. In Proceedings of the 2012 37th International Conference on Infrared, Millimeter, and Terahertz Waves, Wollongong, NSW, Australia, 23-28 September 2012; pp. 1-2. 
107. Fukunaga, K.; Cortes, E.; Cosentino, A.; Stünkel, I.; Leona, M.; Iii, I.N.D.; Mininberg, D.T. Investigating the use of terahertz pulsed time domain reflection imaging for the study of fabric layers of an Egyptian mummy. J. Eur. Opt. Soc. Rapid Publ. 2011, 6, 21. [CrossRef]

108. Koch-Dandolo, C.L.; Filtenborg, T.; Fukunaga, K.; Skou-Hansen, J.; Jepsen, P.U. Reflection terahertz time-domain imaging for analysis of an 18th century neoclassical easel painting. Appl. Opt. 2015, 54, 5123-5129. [CrossRef]

109. Zipfel, W.R.; Williams, R.M.; Webb, W.W. Nonlinear magic: Multiphoton microscopy in the biosciences. Nat. Biotechnol. 2003, 21, 1369-1377. [CrossRef]

110. Rehberg, M.; Krombach, F.; Pohl, U.; Dietzel, S. Label-Free 3D Visualization of Cellular and Tissue Structures in Intact Muscle with Second and Third Harmonic Generation Microscopy. PLoS ONE 2011, 6, e28237. [CrossRef]

111. Cox, G.; Kable, E.; Jones, A.; Fraser, I.; Manconi, F.; Gorrell, M.D. 3-Dimensional imaging of collagen using second harmonic generation. J. Struct. Boil. 2003, 141, 53-62. [CrossRef]

112. Gavgiotaki, E.; Filippidis, G.; Markomanolaki, H.; Kenanakis, G.; Agelaki, S.; Georgoulias, V.; Athanassakis, I. Distinction between breast cancer cell subtypes using third harmonic generation microscopy. J. Biophotonics 2016, 10, 1152-1162. [CrossRef]

113. Mari, M.; Filippidis, G.; Palikaras, K.; Petanidou, B.; Fotakis, C.; Tavernarakis, N. Imaging ectopic fat deposition in caenorhabditis elegans muscles using nonlinear microscopy. Microsc. Res. Tech. 2015, 78, 523-528. [CrossRef]

114. Palikaras, K.; Mari, M.; Petanidou, B.; Pasparaki, A.; Filippidis, G.; Tavernarakis, N. Ectopic Fat Deposition Contributes to Age-Associated Pathology in Caenorhabditis Elegans. J. Lipid Res. 2017, 58, 72-80. [CrossRef]

115. Filippidis, G.; Gualda, E.J.; Melessanaki, K.; Fotakis, C. Nonlinear imaging microscopy techniques as diagnostic tools for art conservation studies. Opt. Lett. 2008, 33, 240-242. [CrossRef]

116. Brown, C.P.; Houle, M.-A.; Popov, K.; Nicklaus, M.; Couture, C.-A.; Laliberté, M.; Brabec, T.; Ruediger, A.; Carr, A.J.; Price, A.J.; et al. Imaging and Modeling Collagen Architecture from the Nano to Micro Scale. Biomed. Opt. Express 2014, 5, 233. [CrossRef]

117. Villafana, T.E.; Delaney, J.K.; Warren, W.S.; Fischer, M.C. High-resolution, three-dimensional imaging of pigments and support in paper and textiles. J. Cult. Heritage 2016, 20, 583-588. [CrossRef]

118. Tserevelakis, G.J.; Tsafas, V.; Melessanaki, K.; Zacharakis, G.; Filippidis, G. Combined multiphoton fluorescence microscopy and photoacoustic imaging for stratigraphic analysis of paintings. Opt. Lett. 2019, 44, 1154-1157. [CrossRef]

119. Oujja, M.; Psilodimitrakopoulos, S.; Carrasco, E.; Sanz, M.; Philippidis, A.; Selimis, A.; Pouli, P.; Filippidis, G.; Castillejo, M. Nonlinear imaging microscopy for assessing structural and photochemical modifications upon laser removal of dammar varnish on photosensitive substrates. Phys. Chem. Chem. Phys. 2017, 19, 22836-22843. [CrossRef]

120. Filippidis, G.; Massaouti, M.; Selimis, A.; Gualda, E.J.; Manceau, J.M.; Tzortzakis, S. Nonlinear Imagig and THz Diagnostic Tools in the Service of Cultural Heritage. Appl. Phys. A 2012, 106, 257-263. [CrossRef]

121. Fovo, A.D.; Sanz, M.; Mattana, S.; Oujja, M.; Marchetti, M.; Pavone, F.; Cicchi, R.; Fontana, R.; Castillejo, M. Safe limits for the application of nonlinear optical microscopies to cultural heritage: A new method for in-situ assessment. Microchem. J. 2020, 154, 104568. [CrossRef]

122. Van der Doelen, G.A.; Van den Berg, K.J.; Boon, J.J. Comparative Chromatographic and Massspectrometric Studies of Triterpenoid Varnishes: Fresh Material and Aged Samples from Paintings. Stud. Conserv. 1998, 43, 249-264.

123. Xu, C.; Wise, F.W. Recent advances in fibre lasers for nonlinear microscopy. Nat. Photon. 2013, 7, 875-882. [CrossRef]

124. Gualda, E.J.; Filippidis, G.; Melessanaki, K.; Fotakis, C. Third-harmonic generation and multi-photon excitation fluorescence imaging microscopy techniques for online art conservation diagnosis. Appl. Spectrosc. 2009, 63, 280-285. [CrossRef]

(C) 2020 by the authors. Licensee MDPI, Basel, Switzerland. This article is an open access article distributed under the terms and conditions of the Creative Commons Attribution (CC BY) license (http://creativecommons.org/licenses/by/4.0/). 